\title{
A Report on "Old Map Collection" by Geospatial Information Authority of Japan
}

\author{
Kana HIDARI $^{\mathrm{a},}$ *, Niina NAKANO ${ }^{\mathrm{b}}$ \\ ${ }^{a}$ Geospatial Information Authority of Japan, Tsukuba, Ibaraki, Japan; hidari-k96es@ mlit.go.jp \\ ${ }^{b}$ Geospatial Information Authority of Japan, Tsukuba, Ibaraki,Japan;nakano-n96as@mlit.go.jp \\ * Corresponding author
}

Keywords: Maps and the Internet, historical maps

\begin{abstract}
:
Historical maps are valuable resources to understand the topography, land use, and land cover of the country in the past. Recently they have been used as basic data in fields such as education, disaster prevention or research on local history.

Geospatial Information Authority of Japan (GSI) has been working on collecting and archiving historical maps which were drawn before than Meiji period. However, public use of these maps is often confined because they are almost nonexistent or have the possibility of being damaged. Therefore, in order for everyone to use these maps, GSI created a website "Old Map Collection" (Figure 1), which provides various digitized historical maps. In this presentation, we introduce the summary of "Old Map Collection" and some of its new contents.
\end{abstract}

In 2005 GSI created a website "Old Map Collection” to provide historical maps for public use as historical, cultural, and academic documents. Users can browse about 1,500 map sheets including various related information, e.g., name, size, date-of-creation, author, and pictorial image. Also all maps are categorized into 15 fields such as maps made in Meiji period, maps of Japan, world maps, and Ino's maps, based on their age of publication, range of area, and purpose of use, which enables users to find maps more easily.

2018 marked the 150th anniversary since the beginning of Meiji period, when the modernization of Japan started. In order to bequeath the history of Meiji to future generations, Japanese government has promoted the policy named "MEIJI 150th". One of the projects GSI conducted related to "MEIJI 150th" was the additional release of 1:20,000 scale original rapid survey map, e.g., Figure 2, on "Old Map Collection". This map was created from 1880 to 1886 (the 13th -19th years of Meiji period) in advance of the national survey by General Staff Office of the Imperial Japanese Army, and is now owned only by GSI. It contains 921 colored map sheets which cover the area of capital Tokyo and its surrounding regions.

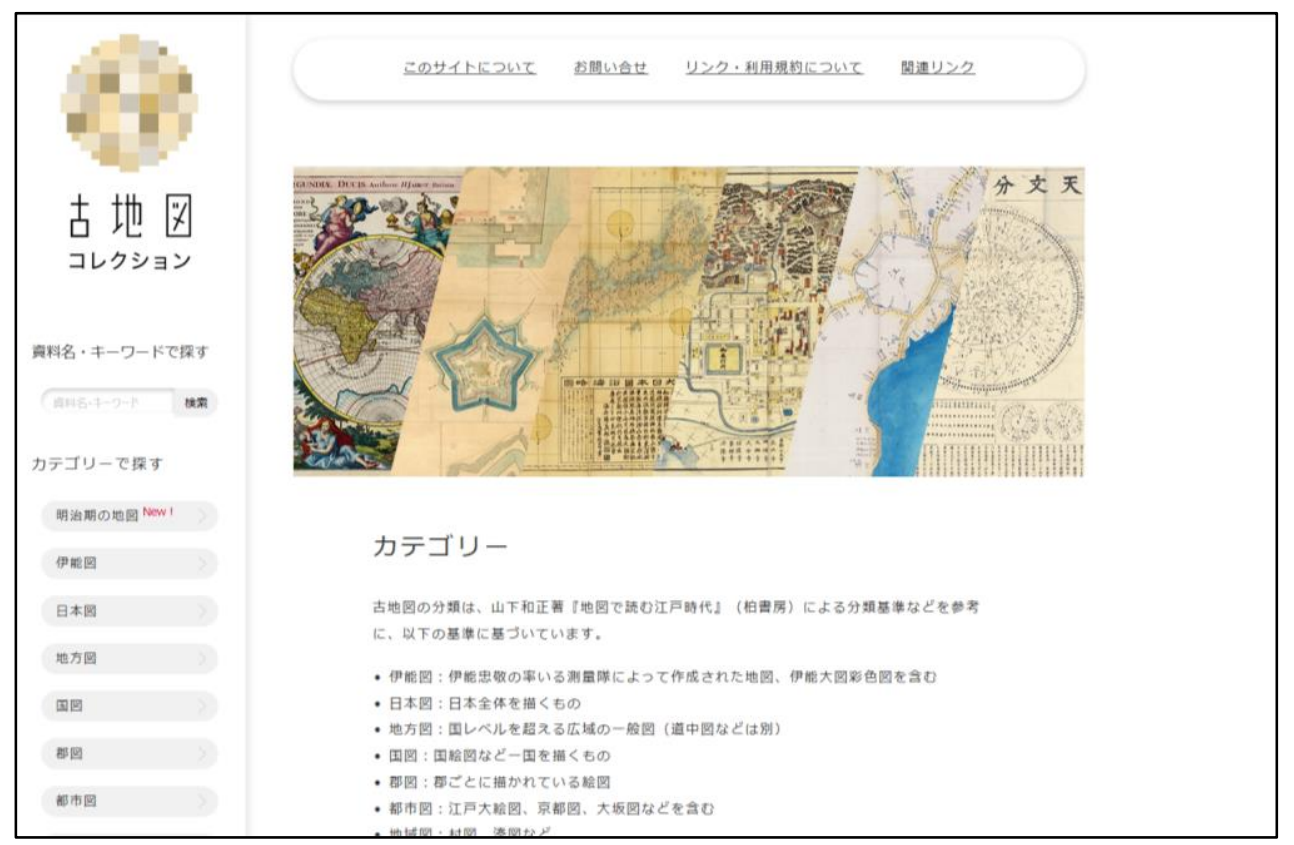

Figure 1. Screen of "Old Map Collection”. 


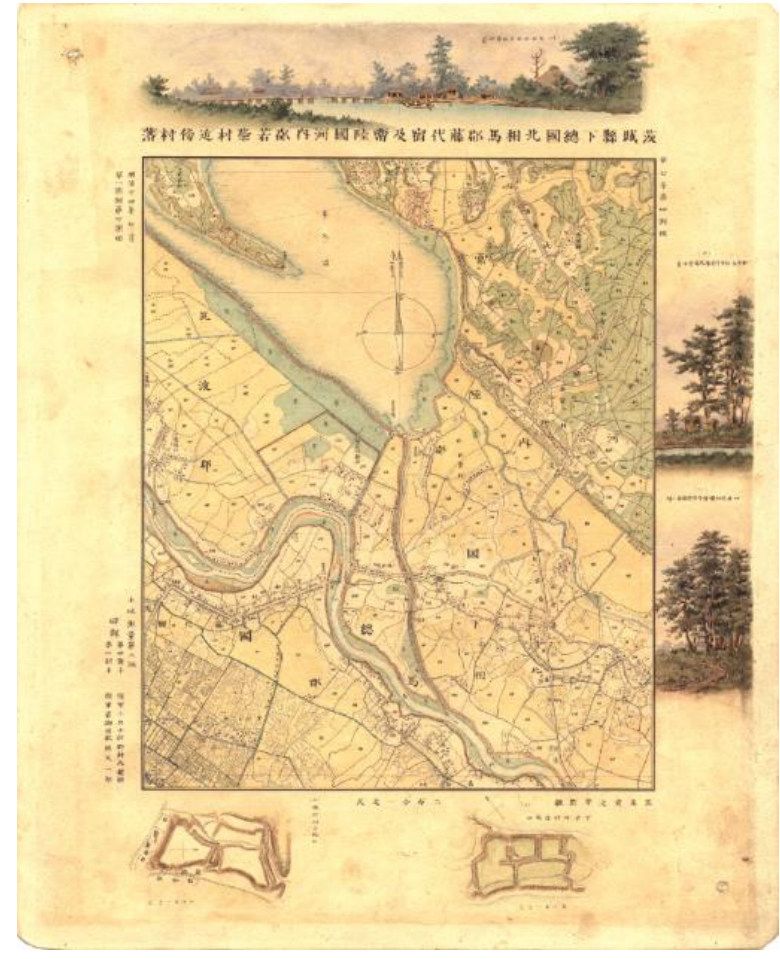

Figure 2. 1:20,000 scale original rapid survey map. 